Golding, S. E. \& Cropley, M (In Press). Effects of community-based interventions on rates of organ donor registration: a systematic narrative review. Progress in Transplantation

\title{
Effects of community-based interventions on rates of organ donor registration: a systematic narrative review
}

\section{Keywords}

Organ donation; donor registration; psychological interventions; behaviour change interventions; systematic review

\begin{abstract}
Background: The demand for organ donation is increasing worldwide. One possible way of increasing the pool of potential posthumous donors is to encourage more members of the general public to join an organ donor registry.

Objective: A systematic review was conducted to investigate the effectiveness of psychological interventions designed to increase the number of individuals in the community who register as organ donors.

Methods: PsycINFO and PubMed databases were searched. No date limits were set. Randomized and non-randomized controlled trials exploring the effects of community-based interventions on organ donor registration rates were included. Methodological quality was assessed using the 'Quality Assessment Tool for Quantitative Studies'.
\end{abstract}


Results: 24 studies met the inclusion criteria; 19 studies found a positive intervention effect on registration. Only eight studies were assessed as having reasonable methodological robustness. A narrative synthesis was conducted. Factors influencing registration rates include providing an immediate registration opportunity and using brief interventions to challenge misconceptions and concerns about organ donation.

Discussion: Community based interventions can be effective at increasing organ donor registrations amongst the general public. Factors that may increase effectiveness include brief interventions to address concerns, and providing an immediate registration opportunity. Particular consideration should be paid to the fidelity of intervention delivery.

Protocol Registration Number: CRD42014012975.

\section{INTRODUCTION}

\section{Background}

The decision to register as an organ donor is influenced by various demographic and psychological factors, as summarised in a recent theoretical review. ${ }^{1}$ However, the evidence is not always clear-cut. One review of cross-sectional surveys found that demographic predictors of donation attitudes and self-reported donor behaviour included education levels, socioeconomic class, religious beliefs, age, and gender. ${ }^{2}$ In contrast, a meta-analysis of demographic factors found that only education and religion were significant predictors of donation attitudes and behaviours, and that gender, ethnicity, and marital status were not related to these outcomes. ${ }^{3}$ Despite this, there is some evidence that messages about organ donation should be culturally sensitive. ${ }^{4}$

The relationship between organ donation beliefs, attitudes, and behaviours is complex. Organ donation is generally considered an altruistic act, but people appear to hold ambivalent attitudes. ${ }^{5}$ Religious beliefs are both positively and negatively correlated with 
positive donation attitudes and behaviours. ${ }^{1}$ Misconceptions about the organ donation process, such as mistrust of the medical system or uncertainty about religious teachings, appear to negatively influence attitudes. ${ }^{6}$ Another key concern is the need to maintain body integrity, which is also negatively associated with donation attitudes. ${ }^{2,6}$ Beyond the cognitive level, negative emotional factors, particularly fear and disgust, are barriers to registration. This has been referred to as the "ick factor' ${ }^{7}$ and these emotional responses have been shown to distinguish between registered and non-registered potential donors. ${ }^{8}$

Interventions to increase donation rates generally fall into two areas. The first area focuses on healthcare professionals involved in approaching the deceased's next-of-kin, and seeks to improve donation rates at this level. ${ }^{9,10}$ Relatives' decisions to agree or decline donation are influenced by their own knowledge and attitudes towards transplantation, knowledge of the deceased's wishes, and the timing and nature of the donation request from clinicians. ${ }^{11,12}$ Indeed, the various approaches adopted by healthcare professionals may account for some of the observed within-country variations. ${ }^{13}$

The second set of interventions focuses on encouraging the general population to register as donors. These are generally designed to influence knowledge, beliefs, and intentions to overcome barriers to registration. Some interventions have been specifically targeted at minority ethnic groups, ${ }^{14,15}$ as these groups are often underrepresented on organ donor registries. Interventions that increase knowledge and challenge misconceptions have had some success in improving rates of pro-donation attitudes and behavioural intentions. ${ }^{4}$ However, people's ambivalence towards organ donation may reduce their motivation to seek additional information. ${ }^{5}$ As a change in attitudes and intentions does not necessarily lead to behaviour change, it is important to identify interventions that lead to changes in actual registration rates. 
Previous systematic reviews of organ donation have focused on potential predictors of attitudes towards organ donation, ${ }^{1,2}$ the importance of next-of-kin beliefs, ${ }^{1}$ and demographic and psychological differences between registered and non-registered potential donors. ${ }^{3} \mathrm{~A}$ meta-analysis of communication interventions examined intervention effects on combined outcome measures (including attitudes, registration, and conversations with family), but did not report any quality assessment of included studies. ${ }^{16}$ One review also explored how communication messages might be better designed, by taking account of psychosocial factors. ${ }^{1}$ Whilst this review provides useful theory-based insights, many of the studies included only explored the effects of interventions on attitudes or intentions. To date, no review has focused on community-based interventions that seek to influence actual registration as a potential organ donor.

\section{Objective}

The objective of this review was therefore to assess the effectiveness of psychological interventions (i.e. those designed to influence knowledge, beliefs, and/or intentions about organ donation) by focusing on studies that measured organ donor registration rates, rather than just changes in psychological constructs. A search of The Cochrane Library, SCOPUS, DARE, and the NICE website (http://www.evidence.nhs.uk) established that no systematic review has already addressed this question.

\section{METHOD}

The protocol for this review was registered on the PROSPERO database; the registration number is CRD42014012975.

\section{Inclusion Criteria for Subject-Studies}


Studies were included in the review only if they met the below criteria. Inclusion criteria were developed using the PICOCS acronym, ${ }^{17}$ as recommended by The Centre for Research and Dissemination (2009) ${ }^{18}$. Only studies published in English were included. No date restrictions were set.

Participants. Members of the general public, not already registered as an organ donor.

Intervention. Community-based, designed to influence beliefs, knowledge, and/or intentions in order to increase registration rates as a posthumous solid organ donor; not interventions targeted at healthcare professionals, patients awaiting transplants, or families of potential donors. Studies aimed at increasing either living donation or blood donation were excluded. Comparator. Either another intervention, or no intervention.

Outcome measures. Actual behaviour (i.e. percentage rates of signing donor card or equivalent) whether objectively or subjectively measured. Studies were excluded if no measure of registration was reported and only changes to knowledge, beliefs etc. were reported.

Context. Delivered in community to general population; no restrictions set regarding exact setting, country, or mode of delivery.

Study design. Randomized controlled trials (RCT) and non-randomized controlled trials (CT).

\section{Search Strategy and Screening}

Electronic databases (PsycINFO and PubMed) were searched during February 2015 using the following search string: organ AND (donat* OR transplant* OR procur* OR regist*) AND (intervention OR education*) AND (trial OR experiment*). Using the symbol * allows all variants of the word ending to be retrieved. 
Titles and abstracts of articles retrieved from databases were screened against the inclusion criteria, to determine the population, outcome measures, and study design. Any studies not excluded were then sourced for full-text reading. Reference lists of any articles deemed eligible for inclusion after full-text reading were also reviewed. Potential articles were then sourced for screening and full-text reading where appropriate; this process continued until no new articles were identified.

\section{Data Extraction}

Data extraction was completed by SG and independently confirmed by MC; any discrepancies were discussed and amendments agreed. Data extracted included study setting, number of participants, and details of the intervention and any control conditions. Details of how registration rates were measured and summaries of main findings were recorded. The reviewers calculated odds ratios wherever possible, based upon data available in the articles.

\section{Assessment of Study Quality}

Initially, assessment was to be made based on the CONSORT statement, ${ }^{19}$ which should provide enough information to judge RCTs. ${ }^{20}$ However, given the complexity of many public health interventions, ${ }^{18}$ and the inclusion of CTs in the review, the Quality Assessment Tool for Quantitative Studies ${ }^{21}$ was selected for assessing methodological quality. It has been recommended for assessing all quantitative studies ${ }^{22}$ and includes an assessment of intervention fidelity. The Quality Assessment Tool for Quantitative Studies ${ }^{21}$ requires studies to be classified as 'weak' if two or more sections are rated 'weak', 'moderate' if only one section is 'weak', and 'strong' if no sections are 'weak'. It should be noted that the tool encourages assessments to be made based on information reported in articles; reviewers are instructed to not make inferences about the authors' intentions. 
One section of the Quality Assessment Tool for Quantitative Studies covers 'data collection methods', and asks whether data collection tools were valid and/or reliable. Although self-report measures of donor status can arguably be considered valid and reliable, self-report measures are vulnerable to respondent biases. Therefore, the tool was adapted to distinguish between studies that used objective and subjective measures; objective data collection tools were rated 'strong', whilst self-report measures were rated 'moderate'. A decision was also taken to include the intervention integrity ratings when determining the global rating.

Studies were independently assessed by each reviewer. Ratings were then compared, and discrepancies discussed until agreement reached. Studies rated 'strong' or 'moderate' contributed more significantly to the findings of the review, than studies rated 'weak' ${ }^{17}$

\section{RESULTS}

A total of 493 articles were identified from electronic searching; a review of reference lists of articles included after full-text reading identified 23 additional articles. No duplicates were identified, so a total of 516 abstracts were retrieved for screening. Following abstract review, 480 articles were excluded. After sourcing the remaining 36 articles for full-text reading, 15 were excluded as follows: three articles did not report interventions, three articles did report interventions but did not report on registration outcomes, eight articles reported interventions but had not included a sufficient comparator group, and one article was an RCT protocol. This resulted in 21 articles meeting the inclusion criteria. Of these, one article reported two studies ${ }^{15}$ and another reported three studies. ${ }^{23}$ The review therefore assessed 24 studies. (See Figure 1 for study flowchart).

\section{Study Characteristics}


Extracted data relating to key study characteristics are reported in Table 1. Although some studies were described as RCTs, after applying the assessment tool all studies were judged to be CTs. In some cases, it was apparent that random allocation of participants had not taken place, but in others a lack of reporting regarding randomization procedures meant it was not possible to tell. Given the nature of the interventions, double or triple blinding was not practical.

The majority of studies were conducted in the USA; four other studies were conducted in European countries. Populations targeted were varied. Most studies recruited from the wider general public; five studies targeted specific ethnic groups. ${ }^{14,15-s t u d y 2,29,31,40}$ Several studies only reported percentages for registration rates, rather than numbers, as data analysis took place on government-collected population-level data. ${ }^{24-27}$ Nine studies did not report participant numbers by condition, but for the studies that did, participants were roughly equal across intervention and comparator groups.

\section{Study Quality}

Details of the study assessments are shown in Table 2. Nine studies used a self-report measure of organ donor registration; fifteen reported an objective measure of registration. Participant demographics were taken at baseline in most studies and the majority appeared to control for this in their analysis. Two studies were assessed as 'strong', 27,28 and six were

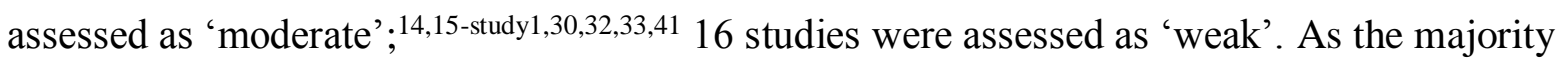
of studies were therefore potentially at higher risk of bias, the reviewers decided not to conduct a meta-analysis. Additionally, comparator groups were varied: interventions were either compared to no intervention at all, practice as usual, or alternative interventions. The narrative synthesis below is therefore based predominantly on findings from the eight studies 
rated 'moderate' or 'strong', although findings from studies rated 'weak' was also integrated where findings were consistent with other studies.

Attrition rates were commented on in around half the articles. Among those that did comment, four reported less than $20 \%$ attrition, ${ }^{27-30}$ five reported between $21 \%$ and $40 \%$ attrition, ${ }^{14,31-34}$ and four reported more than $40 \%$ attrition. ${ }^{35-38}$

\section{Intervention Integrity}

Various interventions were described; all sought to increase registrations by manipulating knowledge, beliefs, and/or intentions about organ donation. Most were delivered directly to the target population, but some involved training people who could influence individuals' decision-making.

Intervention integrity varied across the studies (see Table 2). Some studies reported interventions in reasonable detail, but others did not. Only five studies ${ }^{15}$-study1,15-study2,30,39,41 commented on efforts to judge the consistency of the intervention delivery.

\section{Effects on Registration Rates}

Of 24 studies reviewed, 19 reported an increase in registration as a result of the intervention, but not all effects reached statistical significance. Additionally, rates of increase varied substantially. In studies reporting population-level interventions, a small percentage increase would still have a large impact on registration rates. For smaller interventions, however, registration rates would need to be larger for the intervention to be meaningfully effective; for example, one relatively resource-intensive local-level intervention resulted in only $4.8 \%$ of participants registering, ${ }^{29}$ compared to another that resulted in $86 \%$ of participants registering. ${ }^{15-\text { study2 }}$ 
A lack of significant difference between experimental groups in three studies, ${ }^{14,23-}$ study1,23-study2 may be because these studies only compared different organ donation interventions, and did not include a 'no intervention' control group. Two studies did not report inferential statistics for the intervention effect. ${ }^{31,40}$ One study reported lower registration amongst participants who received a 'Theory of Planned Behaviour' version of the intervention questionnaire, compared to control participants who received no attitudinal manipulation, although participants who received a third variant of the intervention questionnaire did show increased registration. ${ }^{28}$

Most studies reported the primary outcome as a percentage; odds ratios and 95\% confidence intervals were therefore calculated, based on data available in the published articles (see Table 3). In a few cases, odds ratios could not be calculated, either because the control group returned $0 \%$ registration, or because total sample numbers were not reported.

\section{Narrative Synthesis}

Key findings from the studies are presented below. Studies are grouped according to their key manipulations, but there was overlap; the categories that follow are not mutually exclusive.

Increasing knowledge and correcting misconceptions. Most interventions aimed to increase registration by improving participants' knowledge; facts were presented about organ donation and the process of becoming a donor. ${ }^{14,15-s t u d y 1,27,30,32,33,41}$ These 'educational' interventions sought to address commonly held misconceptions or fears. For example, one study presented a video to driving licence and identification card applicants at DMV offices. ${ }^{30}$ The video showed people with diverse demographic characteristics discussing 
concerns around donation, such as the belief that religions may oppose it, or mistrust of the medical system.

Participants across interventions were often exposed to personal stories from donor recipients, donor family members, or those waiting for a transplant; this exposure could be either direct (face-to-face) or indirect (stories relayed via videos or websites). The majority of these 'educational' interventions appeared reasonably successful, despite differences in locations and methods of delivery.

Three studies reported face-to-face interventions. One study used "town hall" style forums, where participants listened to a presentation by an "expert panel", consisting of donor recipients, donor families, and clinicians. ${ }^{15-\text { study1 }}$ Another study was workplace-based, and featured people affected by organ donation attending intervention sites; participants were also encouraged to speak to family members about organ donation. ${ }^{32}$ The third face-to-face intervention took place within DMV offices and included promotional material to increase knowledge. ${ }^{27}$ The intervention also involved having tables staffed by volunteers affected by organ donation, and training of staff members to raise the topic of donation with licence applicants. $^{27}$

Four studies reported interventions that did not involve face-to-face contact to present 'educational' material. In one study, participants were presented with organ donation information via a website, ${ }^{41}$ while in another study, households were mailed brochures and questionnaires about organ donation. ${ }^{33}$ Another study used a brief iPod video to address common concerns about organ donation; the video was shown to people attending DMV offices, who were then asked by staff if they wished to register. ${ }^{30}$ The fourth study specifically aimed to improve knowledge and address emotional concerns amongst African Americans. ${ }^{14}$ Written and visual material designed for this target population was distributed to participants to take home. This study found no significant increases in registration 
compared to the control group; however, control participants had access to currently used organ donation promotional materials, meaning intervention materials appeared comparable, rather than superior to, existing materials.

Manipulating attitudes, intentions, and emotions. Not all studies used an 'educational' approach. One study specifically aimed to elicit an emotional response, by manipulating levels of anticipated regret. ${ }^{28}$ Registrations were highest amongst participants who received the anticipated regret manipulation, compared with two control groups. Additionally, anticipated regret mediated the intention-registration relationship.

Another study explored the effects of additional training for staff at DMV offices, ${ }^{27}$ where DMV clerks are expected to ask applicants to consider joining the organ donor registry. Results showed that by increasing pro-donation attitudes and behavioural intentions amongst DMV clerks, significant increases in registrations were achieved during the intervention period. However, follow-up eight months after the intervention ended revealed that effects were not maintained, suggesting continued efforts may be needed to sustain higher registration rates.

Raising salience and providing registration opportunities. A large study in Sweden compared registration rates in three residential areas: ${ }^{33}$ one area was only exposed to massmedia campaigns, households in another area only received brochures about donation, whilst a third area whose households received brochures was also exposed to the mass-media campaign. Registration rates in the mass-media only area did not change compared to population registration rates across Sweden. In contrast, in the two areas where households received brochures, registration rates were significantly increased. Interestingly, there was no significant difference in rates between these two areas, regardless of whether or not 
households were exposed to the mass-media campaign. This suggests the effects may result from being provided with a convenient opportunity to register, especially as the mass-media campaign alone did not increase registration rates compared to the rest of Sweden.

Only one study explicitly compared the provision of an opportunity to register immediately with a delayed opportunity; significant effects on registration rates were reported. ${ }^{15 \text {-study1 }}$ However, where immediate registration opportunities were provided to intervention and control groups, there were still differences, indicating that other factors (such as emotions and attitudes) can be manipulated to increase likelihood of registration..$^{27,28,30,41}$ Nonetheless, the differences between immediacy and non-immediacy conditions ${ }^{15,33}$ indicate that provision of a registration opportunity should be considered in any intervention.

Location. An apparently successful approach was to target individuals who attended government offices for vehicle licencing. All five studies that intervened in these locations reported significant increases in registrations. ${ }^{24-27,30}$ Although three of these studies were rated 'weak' overall, ${ }^{24-26}$ they described large-scale interventions, targeting whole populations. These positive results support the findings from two similar studies, rated as 'strong' ${ }^{27}$ and 'moderate' ${ }^{30}$ respectively. Interventions targeted at individuals attending DMV offices are inevitably going to exclude certain sections of society; nonetheless, this group of studies suggests population-level interventions can impact on registration rates.

\section{Reports of Potential Harm}

Only two studies mentioned potential for harm. One study reported no adverse effects. ${ }^{30}$ Another study that compared the effects of three different questionnaires, reported potential harms from one comparator condition, which resulted in fewer registrations than the 
main control condition. ${ }^{28}$ This highlights the importance of high quality trials, to ensure interventions do not inadvertently reduce registration rates.

\section{DISCUSSION}

The purpose of the review was to establish whether psychological interventions delivered direct to the general population were effective at increasing organ donor registrations. Overall, most studies reported increased registrations following an intervention, but methodological quality and effect sizes varied. Studies included represented a range of interventions, targeting either knowledge levels, beliefs about donation, and/or intentions to donate, and were delivered to various population samples. Additionally, even where there was an intervention effect, registration rates were not always very high; those designing and evaluating interventions should be mindful that some apparently resource-intensive interventions delivered comparatively small increases in registration. An assessment of costeffectiveness might be a useful addition to future studies as part of the overall evaluation of these interventions.

The elements that seemed effective at increasing registrations were providing an immediate opportunity to register as an organ donor whilst the issue was still salient, and addressing concerns and misconceptions in a clear, yet brief manner, just prior to making a decision about organ donation. Indeed, it has been argued that influencing attitudes may be the wrong focus; efforts should be targeted at the so-called "passive-positives", ${ }^{5}$ who are favourable towards donation, but have not yet registered, by reducing barriers to action. As attitudes towards organ donation are already generally positive, it may be more important to simply provide a registration opportunity. ${ }^{5}$

Targeting DMV offices appears an effective way of increasing registrations, by accessing large parts of the population, but will also inevitably exclude certain sections of 
society. Raising pro-donation attitudes amongst staff at DMV offices may increase registration, but it is likely that refresher training would be needed to maintain any effects.

Future interventions should be sensitive to the context in which they are delivered, and should build on areas identified as contributing to increased registration. Better study design should, however, be employed; studies should ideally use objective measures of registration, as well as ensure any baseline differences are controlled for. Consideration should be given as to how intervention fidelity can be optimized, especially if the intervention is being delivered to staff or community leaders, who are then required to pass on key messages. Attempts should also be made to measure intervention fidelity; although some variation is to be expected, to what extent this might undermine intervention effects should be acknowledged and explored in future research.

Increasing registration rates is therefore possible through community-based interventions, but this is just one aspect of increasing the availability of potential donor organs. Another key moment is the decision made by next-of-kin. Organ donation registries can aid this decision-making process, as, by registering, an individual can make a clear statement about their wishes. When uncertainty about the deceased's wishes regarding their organs was removed, families were more likely to consent to donation. ${ }^{12}$ Effective interventions to encourage people to join organ donor registries are needed to support the growing global trends for solid organ transplantation.

\section{Limitations}

Methodological quality varied, making it difficult to assess the contribution of some studies to the evidence base. Despite a large proportion of the studies being rated as 'weak', the review did however identify some consistent findings across the studies. After completing the assessments, it was decided not to conduct a meta-analysis, due to the possibility of risk 
of bias in the data from those studies rated 'weak'. Furthermore, due to resource issues, the scope of this review did not include searching for 'grey' literature, or unpublished studies, which could potentially limit the findings of this review. Although results were generally suggestive of increased registration rates, confounding variables were not always controlled for effectively. In some cases, intervention fidelity was questionable.

All but four studies were conducted in the USA; whilst this may limit the generalizability of the findings, it also highlights the need for future research to explore the effects of similar interventions in other countries. Perhaps the small group of countries where this research has taken place may be partially explained by legislation; as donor registration rates are generally already very high in countries with an opt-out system, efforts should rightly be focused on increasing registration in countries where registration is opt-in. Nonetheless, there were many countries with opt-in systems that were not represented in the studies reviewed.

\section{Conclusions}

Evidence from this review suggests interventions can be effective at increasing organ donor registrations amongst the general public. Influencing factors include providing an immediate registration opportunity, and using brief interventions to challenge misconceptions and concerns about organ donation. Particular consideration should be paid to intervention fidelity and how this is reported.

\section{REFERENCES}

1. Falomir-Pichastor JM, Berent JA, Pereira A. Social psychological factors of postmortem organ donation: A theoretical review of determinants and promotion 
strategies. Health Psychol Rev. 2013;7(2):202-247.

2. Wakefield CE, Watts KJ, Homewood J, Meiser B, Siminoff LA. Attitudes toward organ donation and donor behavior: a review of the international literature. Prog Transplant. 2010;20(4):380-391.

3. Nijkamp MD, Hollestelle ML, Zeegers MP, Borne B van den, Reubsaet A. To be(come) or not to be(come) an organ donor, that's the question: A meta-analysis of determinant and intervention studies. Health Psychol Rev. 2008;2(1):20-40.

4. Kurz RS, Scharff DP, Terry T, Alexander S, Waterman A. Factors influencing organ donation decisions by African Americans: A review of the literature. Med Care Res Rev. 2007;64(5):475-517.

5. Siegel JT, Alvaro EM, Crano WD, Gonzalez A V, Tang JC, Jones SP. Passive-positive organ donor registration behavior: A mixed method assessment of the IIFF Model. Psychol Health Med. 2010;15(2):198-209.

6. Irving MJ, Tong A, Jan S, et al. Factors that influence the decision to be an organ donor: A systematic review of the qualitative literature. Nephrol Dial Transplant. 2012;27(6):2526-2533.

7. Morgan SE, Stephenson MT, Harrison TR, Afifi WA, Long SD. Facts versus "Feelings": how rational is the decision to become an organ donor? J Health Psychol. 2008;13(5):644-658.

8. O'Carroll RE, Foster C, McGeechan G, Sandford K, Ferguson E. The “ick" factor, anticipated regret, and willingness to become an organ donor. Heal Psychol. $2011 ; 30(2): 236-245$.

9. Young D, Patel S. Effect of "collaborative requesting" on consent rate for organ donation: randomised controlled trial (ACRE trial). BMJ. 2009;339:b3911.

10. Siminoff LA, Marshall HM, Dumenci L, Bowen G, Swaminathan A, Gordon N. 
Communicating effectively about donation: an educational intervention to increase consent to donation. Prog Transplant. 2009;19(1):35-43.

11. Simpkin AL, Robertson LC, Barber VS, Young JD. Modifiable factors influencing relatives' decision to offer organ donation: systematic review. BMJ. 2009;338:b991.

12. Walker W, Broderick A, Sque M. Factors influencing bereaved families' decisions about organ donation: An integrative literature review. West J Nurs Res. 2013;35:1339-1359.

13. NHS Blood and Transplant. Organ Donation and Transplantation: Activity Report 2014/15.; 2015. Available at http://www.odt.nhs.uk/uk-transplant-registry/annualactivity-report/

14. Arriola K, Robinson DH, Thompson NJ, Perryman JP. Project ACTS: An intervention to increase organ and tissue donation intentions among African Americans. Heal Educ Behav. 2010;37(2):264-274.

15. Alvaro EM, Siegel JT, Jones SP. Increasing organ donor registration rates by providing an immediate and complete registration opportunity: An experimental assessment of the IIFF model. Psychol Health Med. 2011;16(6):686-694.

16. Feeley TH, Moon S-I. A meta-analytic review of communication campaigns to promote organ donation. Commun Reports. 2009;22(2):63-73.

17. Petticrew M, Roberts H. Systematic Reviews in the Social Sciences: A Practical Guide. Oxford: Blackwell; 2006.

18. Centre for Research and Dissemination. Systematic Reviews: CRD's guidance for undertaking systematic reviews in health care. Available at http://www.york.ac.uk/inst/crd/pdf/Systematic_Reviews.pdf. Published 2009.

19. Altman DG. Better reporting of randomised controlled trials: the CONSORT statement. BMJ. 1996;313(7057):570-571. 
20. Greenhalgh T. How to Read a Paper: The Basics of Evidence-Based Medicine. 5th ed. Chichester: Wiley-Blackwell/BMJ Books; 2014.

21. Effective Public Health Practice Project. Quality assessment tool for quantitative studies. Available at http://www.ephpp.ca/PDF/Quality Assessment Tool_2010_2.pdf. Published 2010.

22. The Cochrane Collaboration. Cochrane Handbook for Systematic Reviews of Interventions. Version 5. (Higgins J, Green S, eds.). The Cochrane Collaboration; 2011.

23. Birkimer JC, Barbee AP, Francis M Lou, Berry MM, Deuser PS, Pope JR. Effects of refutational messages, thought provocation, and decision deadlines on signing to donate organs. J Appl Soc Psychol. 1994;24(19):1735-1761.

24. Harrison TR, Morgan SE, Di Corcia MJ. Effects of information, education, and communication training about organ donation for gatekeepers: Clerks at the Department of Motor Vehicles and organ donor registries. Prog Transplant. 2008;18(4):301-309.

25. Harrison TR, Morgan SE, King AJ, et al. Promoting the Michigan organ donor registry: Evaluating the impact of a multifaceted intervention utilizing media priming and communication design. Health Commun. 2010;25(8):700-708.

26. Harrison TR, Morgan SE, King AJ, Williams E a. Saving lives branch by branch: The effectiveness of driver licensing bureau campaigns to promote organ donor registry sign-ups to African Americans in Michigan. J Health Commun. 2011;16(8):805-819.

27. Rodrigue JR, Krouse J, Carroll C, Giery KM, Fraga Y, Edwards E. A Department of Motor Vehicles intervention yields moderate increases in donor designation rates. Prog Transplant. 2012;22(1):18-24.

28. O'Carroll RE, Dryden J, Hamilton-Barclay T, Ferguson E. Anticipated regret and 
organ donor registration - A pilot study. Heal Psychol. 2011;30(5):661-664.

29. Resnicow K, Andrews AM, Beach DK, et al. Randomized trial using hair stylists as lay health advisors to increase donation in African Americans. Ethn Dis. 2010;20(3):276-281.

30. Thornton JD, Alejandro-Rodriguez M, León JB, et al. Effect of an iPod video intervention on consent to donate organs: A randomized trial. Ann Intern Med. 2012;156(7):483-490.

31. Arriola K, Robinson DHZ, Perryman JP, Thompson NJ, Russell EF. Project ACTS II: Organ donation education for African American adults. Ethn Dis. 2013;23(2):230-237.

32. Quinn MT, Alexander GC, Hollingsworth D, O’Connor KG, Meltzer D. Design and evaluation of a workplace intervention to promote organ donation. Prog Transplant. 2006;16(3):253-259.

33. Sanner MA, Hedman H, Tufveson G. Evaluation of an organ-donor-card campaign in Sweden. Clin Transplant. 1995;9(4):326-333.

34. Winkel FW. Public communication on donorcards: A comparison of persuasive styles. Soc Sci Med. 1984;19(9):957-963.

35. Morgan S, Miller J, Arasaratnam L. Signing cards, saving lives: An evaluation of the worksite organ donation promotion project. Commun Monogr. 2002;69(3):253-273.

36. Morgan S, Harrison TR, Chewning L V., DiCorcia MJ, Davis L a. The Workplace Partnership for Life: The effectiveness of high- and low-intensity worksite campaigns to promote organ donation. Commun Monogr. 2010;77(3):341-356.

37. Morgan S, Stephenson MT, Afifi W, Harrison TR, Long SD, Chewning LV. The University Worksite Organ Donation Project: A comparison of two types of worksite campaigns on the willingness to donate. Clin Transplant. 2011;25(4):600-605.

38. Winkel FW, Huismans SE. Refutational messages on donor cards: A test of 
boomerang effects. Psychol Rep. 1986;59(2):899-910.

39. Siegel JT, Alvaro EM, Crano WD, Lac A, Ting S, Jones SP. A quasi-experimental investigation of message appeal variations on organ donor registration rates. Heal Psychol. 2008;27(2):170-178.

40. Andrews AM, Zhang N, Magee JC, Chapman R, Langford AT, Resnicow K.

Increasing donor designation through black churches: Results of a randomized trial. Prog Transplant. 2012;22(2):161-167.

41. Vinokur AD, Merion RM, Couper MP, Jones EG, Dong Y. Educational web-based intervention for high school students to increase knowledge and promote positive attitudes toward organ donation. Heal Educ Behav. 2006;33(6):773-786. 
Figure 1. PRISMA Flowchart showing number of studies identified through searching and final number of studies included and excluded from review

Records identified through database searching $(n=493)$
Additional records identified through other sources (hand-searching, $n=23$ )

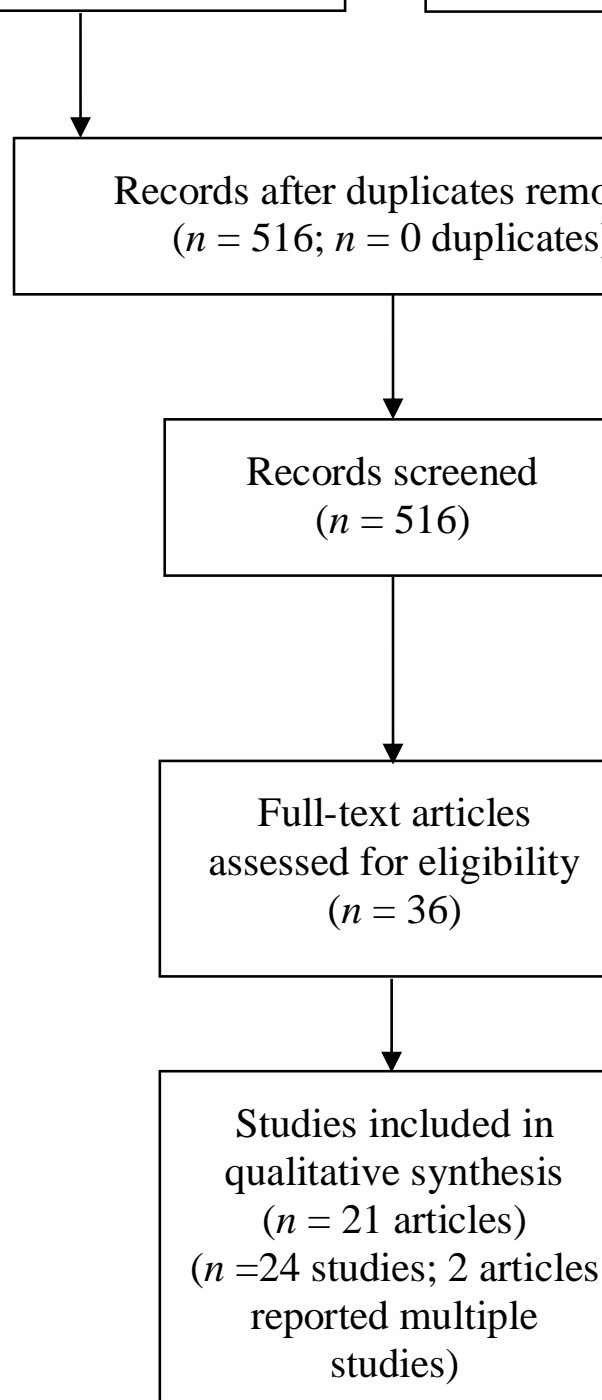

Records excluded $(n=480)$

Full-text articles excluded $(n=15)$ 
Table 1. Characteristics of Studies Included in the Review

\begin{tabular}{|c|c|c|c|c|c|}
\hline $\begin{array}{l}\text { Authors, } \\
\text { Year }\end{array}$ & Setting \& participants & Intervention & Control / comparator & $\begin{array}{l}\text { Objectively } \\
\text { measured } \\
\text { outcome? }\end{array}$ & Main findings \\
\hline Alvaro et & "Town halls", USA $(n=$ & Immediacy: OD forum, & Non-immediacy: OD forum, & Yes & Significantly higher rates of registration \\
\hline al., 2011 & 2 per city): Chicago & followed by distribution of & followed by distribution of & & in immediacy (40.4\%) compared to \\
\hline \multirow[t]{6}{*}{$(\text { Study } 1)^{15}$} & (churches), Miami & donor registration forms \& & donor registration forms $\&$ & & non-immediacy condition (10.3\%). \\
\hline & (local organizations) \& & collection at end of session $(n$ & participants asked to mail & & \\
\hline & Phoenix (universities). & $=104)$ & donor forms later; SAE- & & \\
\hline & 211 individuals: self- & & envelope provided $(n=107)$ & & \\
\hline & selected responders to & & & & \\
\hline & adverts for OD forum & & & & \\
\hline Alvaro et & "Swap meet" (flea & Immediacy: booth erected & Non-immediacy: booth & Yes & Significantly higher rates of registration \\
\hline al., 2011 & market) popular with & with info. about OD \& & erected with same info. & & in immediacy ( $86 \%$ ) compared to non- \\
\hline \multirow[t]{3}{*}{$(\text { Study } 2)^{15}$} & Hispanics, Arizona, & opportunity for registration - & material \& opportunity for & & immediacy condition (54\%). \\
\hline & USA. Info. booths & two large banners saying & registration, but banners & & \\
\hline & erected over 8 & 'Register Here!' \& 'Register & carried phrase 'Donate Life' & & \\
\hline
\end{tabular}




\begin{tabular}{|c|c|c|c|c|c|}
\hline & consecutive weekends. & Now!', intended to advertise & $(n=69)$ & & \\
\hline & 156 members of public & the immediate opportunity to & & & \\
\hline & who entered OD booth & register $(n=87)$ & & & \\
\hline Andrews et & African-American & 'Peer Leaders' from churches & As intervention, except 'Peer & Yes & 211 verified registrations: 163 from \\
\hline \multirow[t]{7}{*}{ al., $2012^{40}$} & churches, South-East & trained in OD educational & Leaders' trained in healthy & & intervention churches $\& 48$ from \\
\hline & Michigan, USA $(n=$ & programme, who subsequently & living educational & & comparison churches. Only 19 verified \\
\hline & 22). 1254 individuals & delivered programme to & programme ( $n=$ unknown; & & registrations could be tied to individuals \\
\hline & completed baseline & congregations at various & intervention offered to & & who completed baseline surveys. No. \\
\hline & survey, recruited & church events ( $n=$ unknown; & whole congregation at 11 & & not reported for total participants \\
\hline & through community & intervention offered to whole & churches) & & receiving intervention. No statistical \\
\hline & events held in church & congregation at 11 churches) & & & analysis reported. \\
\hline Arriola et & Churches in South East & Distribution of Project ACTS & Distribution of donor card, & No, self- & No significant differences between ctrl. \\
\hline \multirow[t]{6}{*}{ al., $2010^{14}$} & $\mathrm{USA}(n=9)$ & videotapes, written materials, & publicly available written & report. & $(48.8 \%) \&$ intervention $(46.9 \%)$ \\
\hline & 452 individuals & donor card \& other items & materials \& items such as & & conditions for being indentified as \\
\hline & recruited; 337 & magnets with project logo; to & pens \& bookmarks; also & & donor on driving licence. No significant \\
\hline & completed 1-year & be taken home \& reviewed by & advised OD videos could be & & differences between ctrl. (24.7\%) \& \\
\hline & follow-up survey & participants during following & borrowed from church & & intervention $(24.0 \%)$ conditions for \\
\hline & & year. Reminders sent to & library. For review at home & & being indentified as donor on donor \\
\hline
\end{tabular}




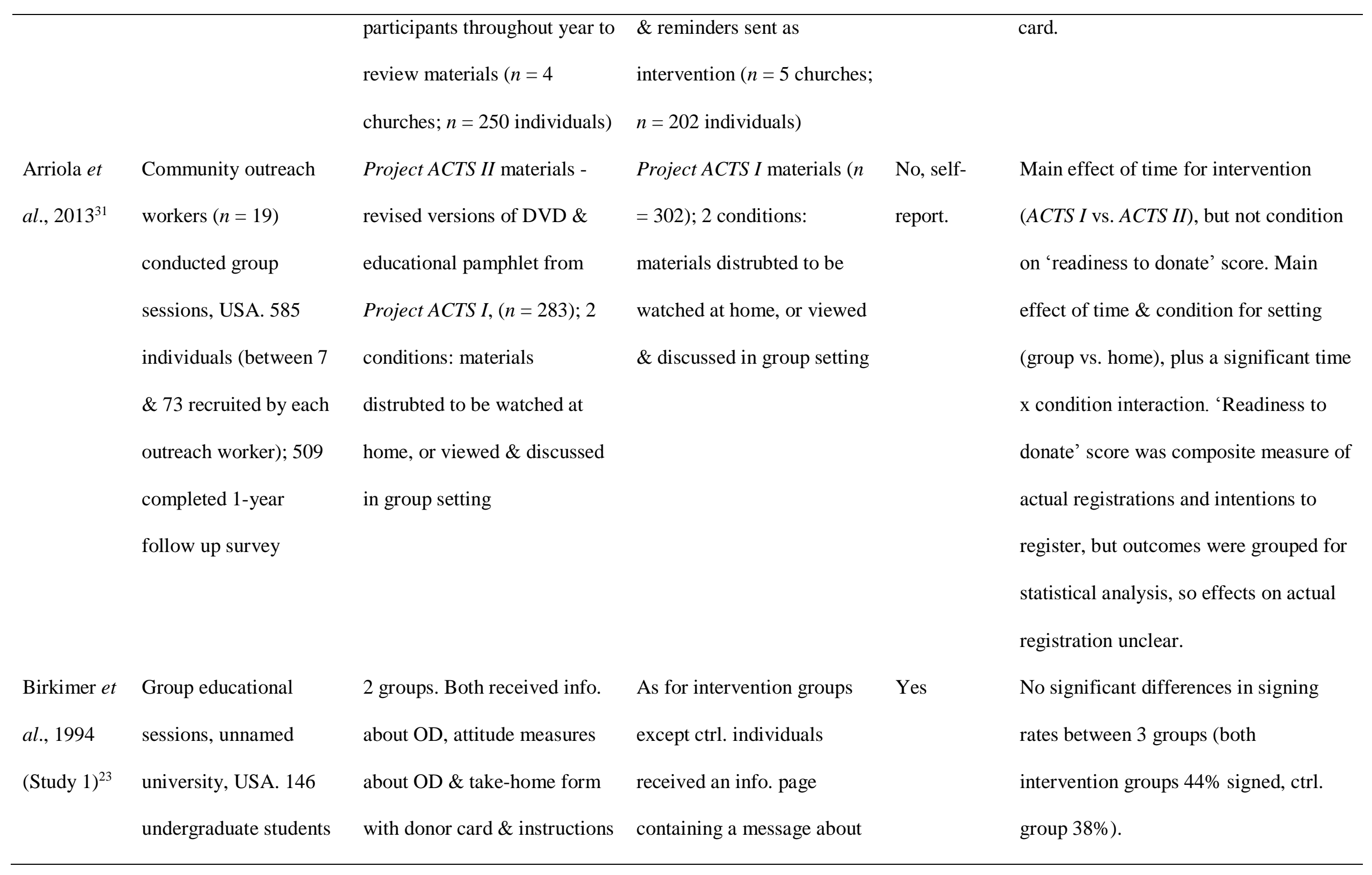




\begin{tabular}{|c|c|c|c|c|c|}
\hline \multirow[b]{5}{*}{ Birkimer et } & \multirow[b]{5}{*}{ Group educational } & \multirow{3}{*}{$\begin{array}{l}\text { for signing driver's licence. } 1 \\
\text { group also received family } \\
\text { discussion guide about OD. ( } n\end{array}$} & \multicolumn{3}{|l|}{ nutritional value of red meat, } \\
\hline & & & \multicolumn{3}{|l|}{ instead of about OD $(n=$} \\
\hline & & & \multicolumn{3}{|l|}{ unknown) } \\
\hline & & \multicolumn{4}{|l|}{ = unknown) } \\
\hline & & $1^{\text {st }}$ group received materials as & Session 1 \& 2. As in Study & Yes & College students: $0 \%$ registration in ctrl. \\
\hline al., 1994 & sessions, unnamed & Study $1 ; 2^{\text {nd }}$ group not given & 1: individuals received info. & & group, compared to $19 \%$ in 'info' group \\
\hline \multirow[t]{8}{*}{$(\text { Study } 2)^{23}$} & college \& university, & info., but asked to think about & about red meat, but instead & & $\& 26 \%$ in 'thinking' group. Both \\
\hline & USA. 233 college & signing as organ donor for 2 & of pre- \& post-test questions & & intervention groups significantly \\
\hline & students \& 71 university & minutes. Half of each group & \multicolumn{2}{|l|}{ about OD, attitude measures } & different from ctrl. group, but not each \\
\hline & students & also asked to discuss OD with & \multicolumn{2}{|l|}{ were about red meat } & other. University students: $14 \%$ \\
\hline & & family; other half instructed & \multicolumn{2}{|l|}{ consumption. College } & registration in intervention group, but \\
\hline & & not to discuss with others. & \multicolumn{2}{|l|}{ students only ( $n=$ unknown) } & no ctrl. group amongst university \\
\hline & & \multicolumn{3}{|l|}{ College \& university students } & participants. \\
\hline & & \multicolumn{4}{|l|}{ ( $n=$ unknown $)$} \\
\hline Birkimer et & Group educational & 3 interventions. TMT 1 = OD & No ctrl. group, but 2 types of & Yes & No significant differences in signing \\
\hline al., 1994 & sessions, unnamed & info.; TMT 2 = OD info., plus & sign up sheet (1 specified & & rates between 3 groups: TMT $1=26 \%$, \\
\hline \multirow[t]{2}{*}{$(\text { Study } 3)^{23}$} & college, USA. 260 & instruction to set a date to & \multicolumn{2}{|l|}{ regular contact with family } & TMT $2=34 \%$, TMT $3=40 \%$ \\
\hline & college students $(1 / 3$ in & decide whether or not to sign & \multicolumn{2}{|l|}{$\& 1$ did not) and 2 types of } & \\
\hline
\end{tabular}




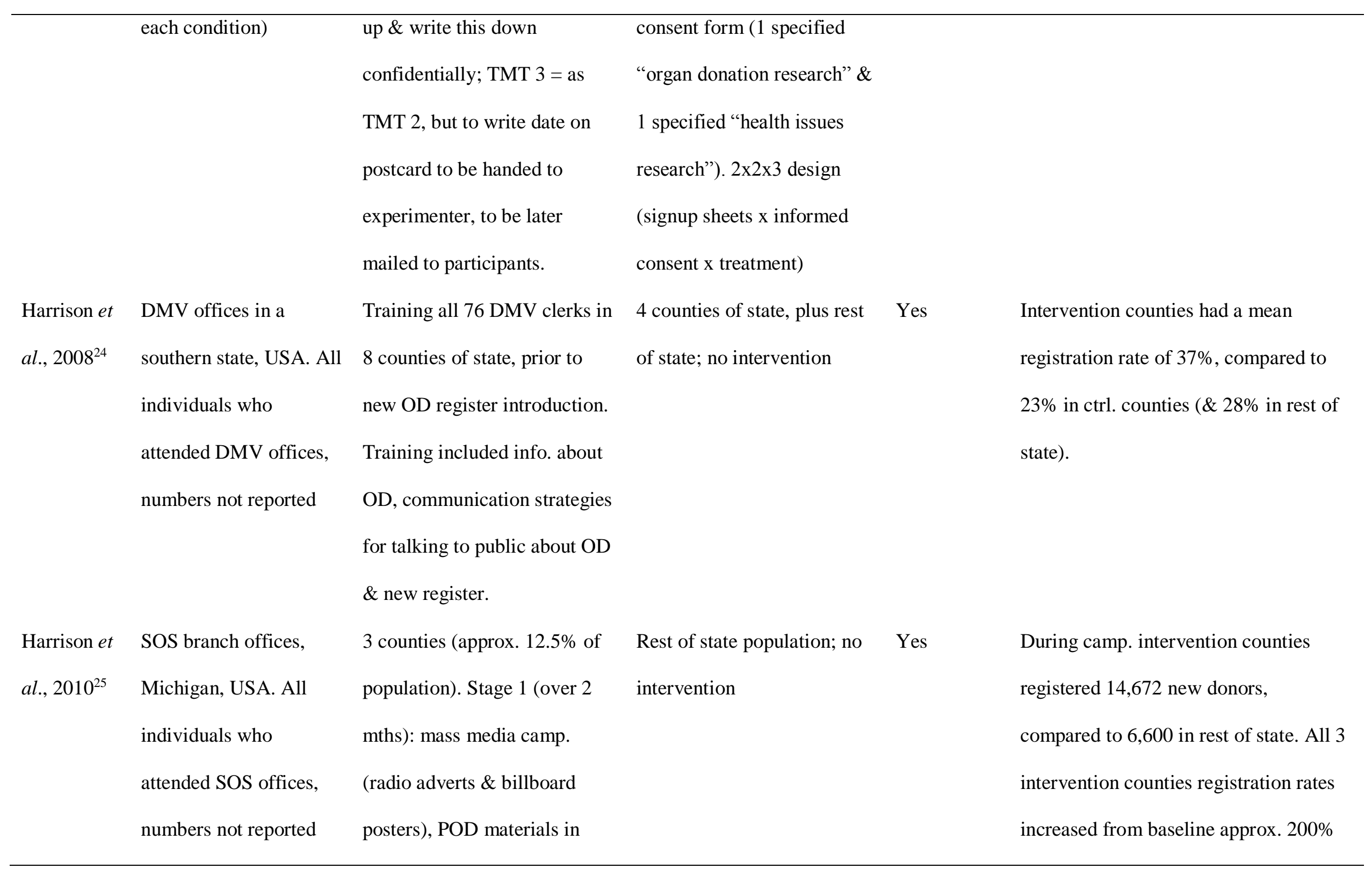


SOS offices. Stage 2 (next 2

mths): as Stage 1, plus

volunteers in SOS offices.

Stage 3: POD materials only.

Harrison et SOS branch offices,

2 counties. Stage 1 (over 2

Rest of state population -

Yes

al., $2011^{26}$ Michigan, USA, with

mths): mass media camp.

additional focus on

(radio adverts \& billboard

African Americans. All

individuals who

attended SOS offices,

numbers not reported

posters), POD materials in

SOS offices. Stage 2 (next 2

mths): as Stage 1, plus

volunteers in SOS offices.

Stage 3: POD materials only.

Morgan et 2 worksites of large,

al., $2002^{35}$ national delivery

corporation, USA, with

approx. 16,000

individuals. $10 \%$

(stratified by occ. class)
Mass-media site: in-house

newspaper articles, intrane

homepage, billboards on

nearby roads, radio adverts,

educational sessions, OPO

volunteer-staffed info. tables materials ( $n=$ unknown, but

at least 149 post-test surveys

relate to ctrl. site)
Ctrl. site: no intervention

during Stage 1, \& approx. 300\% during

Stage 2. State-wide registration rates

increased approx. 5\% \& 9\% during

these times.

During camp. intervention counties

registered 38,951 new donors,

compared to 49,670 in rest of state.

Both intervention counties registration

rates increased from baseline $178 \%$

during Stage 1, \& 357\% during Stage 2 .

State-wide registrations increased

approx. $4 \%$ \& $160 \%$ during these times.

No, self-

report
Significantly more participants reported

having signed a donor card at

intervention site $(52 \%)$ compared to

ctrl. site $(39 \%)$. 
sample pre- $(n=798) \& \quad(n=$ unknown, but at least 401

post-test $(n=552) \quad$ post-test surveys relate to

surveys intervention site)

\begin{tabular}{|c|c|c|c|c|c|}
\hline Morgan et & 45 companies, across & 10 week camp., 2 conditions. & Ctrl. site: no materials & Yes \& no & Significant differences in self reported \\
\hline$a l ., 2010^{36}$ & various industries; 15 & Low-intensity condition: & received before post-test & (two & signing of donor card amongst surveyed \\
\hline & worksites in each & brochures about OD, OD & survey; received modified & measures) & samples: ctrl. (42.8\%), low-intensity \\
\hline & condition, New Jersey, & registry card, adverts \& & camp. afterwards $(n=$ & & (45.9\%), high-intensity (49.7\%). Report \\
\hline & USA. 3,528 individuals & newsletter stories about OD. & unknown) & & $<1 \%$ of employees in low-intensity \& \\
\hline & completed both pre- \& & High-intensity condition: as & & & approx. $6 \%$ of employees in high- \\
\hline & post-test surveys & low-intensity, plus project & & & intensity conditions returned new \\
\hline & & staff \& volunteer-staffed info. & & & registrations; nothing reported for ctrl. \\
\hline & & tables $(n=$ unknown $)$ & & & No statistical analysis reported. \\
\hline Morgan et & 6 universities, across & 2 conditions. Mass-media & Ctrl. sites: received no & No, self- & No significant difference in increase in \\
\hline al., $2011^{37}$ & USA; 2 sites per & condition: adverts in & intervention materials $(n=$ & report & registrations between ctrl. (5\%) \& mass- \\
\hline & condition. $8 \%$ of & university newspapers \& on & unknown) & & media only $(6 \%)$ conditions. \\
\hline
\end{tabular}




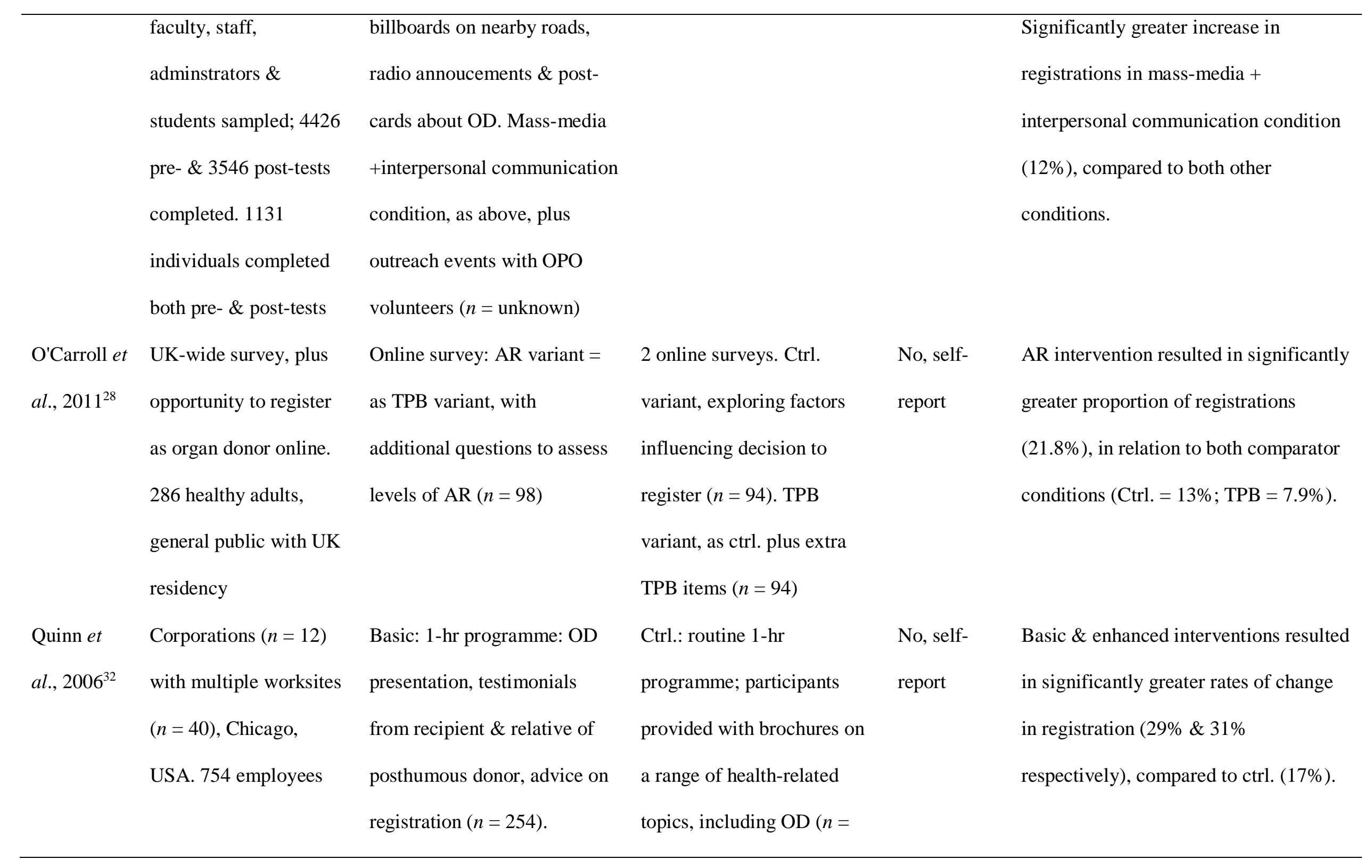




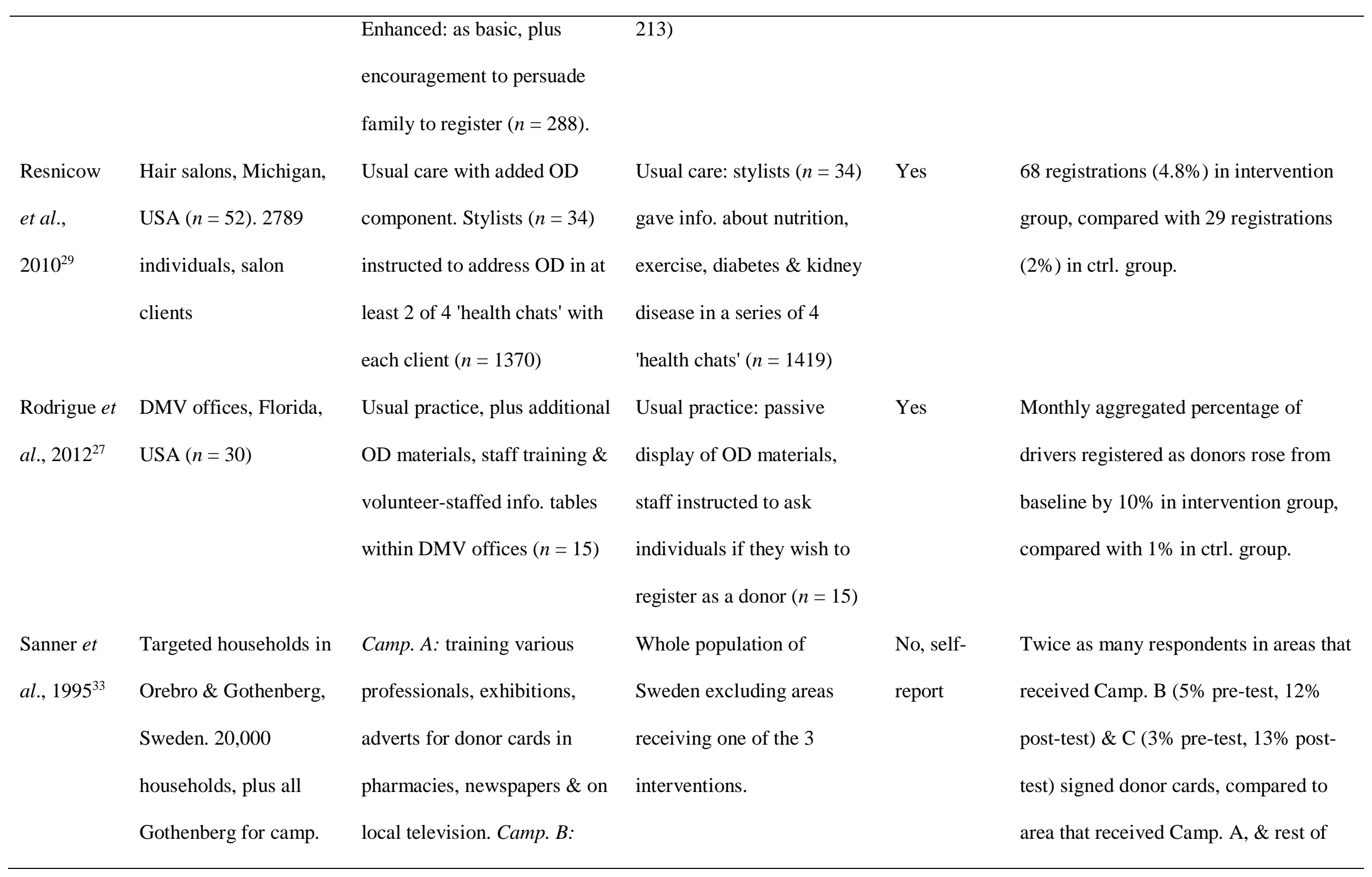




\begin{tabular}{|c|c|c|c|c|c|}
\hline & A. Pre- \& post-test & brochure sent to households ( $n$ & & & Sweden (both unchanged at 5\%). \\
\hline & measures from samples & $=10,000)$ including 2 donor & & & \\
\hline & of each group $(n=1400$ & cards, in Orebro. Camp. $C$ : & & & \\
\hline & for each condition; 700 & brochure sent to households ( $n$ & & & \\
\hline & pre-test \& a different & $=10,000)$ including 2 donor & & & \\
\hline & 700 post-test) & cards, in Orebro & & & \\
\hline Siegel et & Kiosks in 4 settings: & Posters placed in kiosks. & $4 \times 4 \times 4$ design $(64$ & Yes & 421 individuals registered. \\
\hline \multirow[t]{8}{*}{ al., $2008^{39}$} & hospitals, libraries, & Posters delivered 4 types of & conditions): each 'Appeal' & & Tests of main effects significant for \\
\hline & universities, community & 'Appeal', using 4 'Exemplar' & \& 'Exemplar' & & each variable ('Appeal', 'Exemplar' \& \\
\hline & colleges, Tucson, & variations. Kiosks had & counterbalanced across each & & Location). Some variable levels were \\
\hline & Arizona, USA $(n=16$ & registration-dedicated & location $=16$ messages, each & & more effective: counterargument most \\
\hline & 4 kiosks in each & computer. Only completed & rotated through locations & & effective form of 'Appeal' \& excuse \\
\hline & location type) & registrations recorded; total & over 8 weeks; each variant & & format most effective form of \\
\hline & & no. of visits not known. & displayed in 2 of each & & 'Exemplar'. Hospitals \& libraries \\
\hline & & & location type & & resulted in more registrations. \\
\hline Thornton et & BMV branches, Ohio, & Video viewed on iPod outside & Usual BMV practice, staff & Yes & Intervention participants significantly \\
\hline \multirow[t]{2}{*}{ al., $2012^{30}$} & USA $(n=12) .952$ & BMV branch prior to entering & expected to ask individuals & & more likely than ctrl. participants to \\
\hline & applicants visiting & for application, usual practice & if they wish to register as & & consent to OD, ( $84 \%$ vs. $72 \%)$ \\
\hline
\end{tabular}




\begin{tabular}{|c|c|c|c|c|c|}
\hline & BMV branch & continues inside $(n=443)$ & organ donor $(n=509)$ & & \\
\hline Vinokur et & Websites about OD & 2 groups directed to OD & 1 group directed to & Yes & Participants who viewed 'The Journey' \\
\hline \multirow[t]{5}{*}{ al., $2006^{41}$} & ('The Journey') \& & website. 1 group pre- \& post- & common-cold website, & & more likely to contact registry $(21.8 \%)$ \\
\hline & common-cold; 490 high & test measures $(n=152)$. Other & answered pre- $\&$ post-test & & than those who viewed common-cold \\
\hline & school students, & group only post-test measures & measures $(n=159)$. & & website ( $15.7 \%)$; unclear from methods \\
\hline & Michigan, USA. & $(n=179)$ & & & whether this contact always resulted in \\
\hline & & & & & actual registration. \\
\hline Winkel, & Survey, over 2 weeks & 2 exp. conditions: long-form & 2 variations of ctrl. survey; & No, not & No. of applications from 'refutational' \\
\hline \multirow[t]{8}{*}{$1984^{34}$} & around Free University, & survey plus either & one version asked no & cross & condition (40\%) significantly more than \\
\hline & Amsterdam, The & 'conventional' $(n=96)$ or & questions about negative & checked to & ctrl. (27\%), but not significantly more \\
\hline & Netherlands. 1012 & 'refutational' $(n=97)$ info. & behavioural consequences. & registry & than 'conventional' $(34 \%$; also not \\
\hline & surveys issued to & about OD. Included donor & No info. about OD provided. & & significantly different from ctrl.) \\
\hline & students to complete at & registration form & Included donor registration & & \\
\hline & home; 651 returned & & form $(n=228)$ & & \\
\hline & (230 excluded; already & & & & \\
\hline & donor card holders) & & & & \\
\hline Winkel \& & Survey 'over a few & Exp. group received survey, & Ctrl. group received survey & No, not & Registrations higher in exp. than ctrl. \\
\hline Huismans, & weeks' in Weesp, The & donor registration form \& & $\&$ donor registration form & cross & condition. Participants grouped by high \\
\hline
\end{tabular}




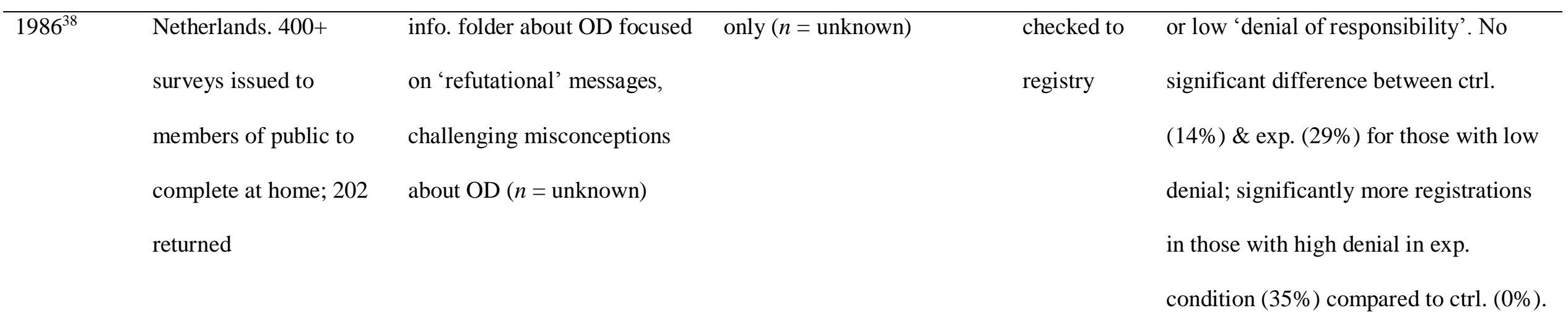

Abbreviations. Approx. = approximately; AR = anticipated regret; BMV = Bureau of Motor Vehicles; Camp. = campaign; Ctrl. = control; DMV =

Department of Motor Vehicles; Exp. = experimental; Hr = hour; Info. = information; Mths = months; No. = number; Occ. = occupational; OD =

organ donation; $\mathrm{OPO}=$ organ procurement organization; $\mathrm{POD}=$ point-of-decision; $\mathrm{SOS}=$ Secretary of State; TPB = Theory of Planned Behaviour 
Table 2. Quality Assessment of Studies Included in the Review

\begin{tabular}{|c|c|c|c|c|c|c|c|c|c|}
\hline Authors, Year & $\begin{array}{l}\text { Selection } \\
\text { bias }\end{array}$ & $\begin{array}{l}\text { Study } \\
\text { design }\end{array}$ & Confounders & Blinding & $\begin{array}{l}\text { Data } \\
\text { collection } \\
\text { methods }\end{array}$ & $\begin{array}{l}\text { Withdrawals } \\
\text { \& drop-outs }\end{array}$ & $\begin{array}{l}\text { Intervention } \\
\text { integrity }\end{array}$ & $\begin{array}{l}\text { Analyses } \\
\text { Appropriate } \\
\text { (Yes / No / } \\
\text { Unable to } \\
\text { determine) }\end{array}$ & $\begin{array}{l}\text { Global } \\
\text { rating }\end{array}$ \\
\hline $\begin{array}{l}\text { Alvaro et al., } 2011 \text { (Study } \\
\text { 1) }\end{array}$ & Weak & Strong & Strong & Moderate & Strong & Strong & Strong & Yes & Moderate \\
\hline $\begin{array}{l}\text { Alvaro et al., } 2011 \text { (Study } \\
\text { 2) }\end{array}$ & Weak & Strong & Weak & Moderate & Strong & Weak & Weak & Yes & Weak \\
\hline Andrews et al., 2012 & Weak & Strong & Weak & Moderate & Strong & Weak & Weak & $\begin{array}{l}\text { Unable to } \\
\text { determine }\end{array}$ & Weak \\
\hline Arriola et al., 2010 & Moderate & Strong & Moderate & Moderate & Moderate & Moderate & Weak & Yes & Moderate \\
\hline Arriola et al., 2013 & Weak & Strong & Strong & Moderate & Moderate & Weak & Weak & Yes & Weak \\
\hline $\begin{array}{l}\text { Birkimer et al., } 1994 \\
\text { (Study 1) }\end{array}$ & Moderate & Strong & Weak & Moderate & Strong & Weak & Weak & Yes & Weak \\
\hline Birkimer et al., 1994 & Moderate & Strong & Weak & Moderate & Strong & Weak & Weak & Yes & Weak \\
\hline
\end{tabular}




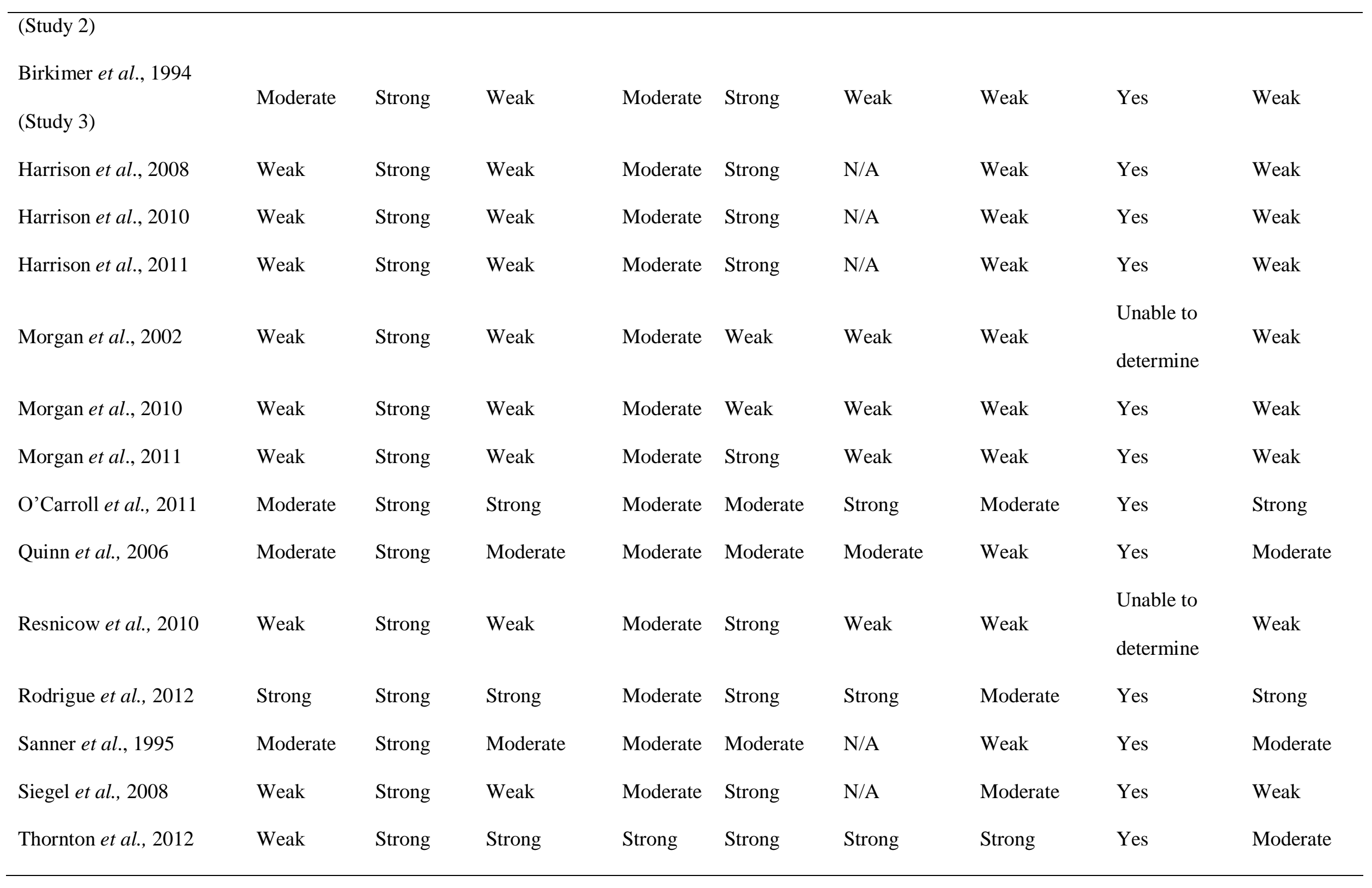




\begin{tabular}{|c|c|c|c|c|c|c|c|c|c|}
\hline Vinokur et al., 2006 & Strong & Strong & Strong & Moderate & Moderate & Weak & Strong & Yes & Moderate \\
\hline Winkel, 1984 & Weak & Strong & Moderate & Moderate & Moderate & Moderate & Weak & Yes & Weak \\
\hline $\begin{array}{l}\text { Winkel \& Huismans, } \\
1986\end{array}$ & Weak & Strong & Strong & Moderate & Moderate & Weak & Weak & Yes & Weak \\
\hline
\end{tabular}


Table 3. Calculated Odds Ratios and 95\% Confidence Intervals (CI)

\begin{tabular}{|c|c|c|c|}
\hline Authors, Year & Odds ratio & Lower 95\% CI & Upper $95 \%$ CI \\
\hline Alvaro et al., 2011 (Study 1) & 5.90 & 2.76 & 12.60 \\
\hline Alvaro et al., 2011 (Study 2) & 5.23 & 2.63 & 10.41 \\
\hline Andrews et al., 2012 & N/A & N/A & N/A \\
\hline \multicolumn{4}{|l|}{ Arriola et al., 2010} \\
\hline Licence & 1.08 & 0.62 & 1.88 \\
\hline Card & 1.04 & 0.54 & 1.98 \\
\hline Arriola et al., 2013 & N/A & N/A & N/A \\
\hline Birkimer et al., 1994 (Study 1) & 1.28 & 0.73 & 2.26 \\
\hline Birkimer et al., 1994 (Study 2) & N/A & N/A & N/A \\
\hline \multicolumn{4}{|l|}{ Birkimer et al., 1994 (Study 3) } \\
\hline Treatment 2 & 1.47 & 0.80 & 2.70 \\
\hline Treatment 3 & 1.90 & 1.04 & 3.46 \\
\hline Harrison et al., 2008 & 1.97 & 1.06 & 3.65 \\
\hline Harrison et al., 2010 & N/A & N/A & N/A \\
\hline Harrison et al., 2011 & N/A & N/A & N/A \\
\hline Morgan et al., 2002 & 1.69 & 0.97 & 2.97 \\
\hline \multicolumn{4}{|l|}{ Morgan et al., 2010} \\
\hline High-intensity & 1.32 & 0.76 & 2.30 \\
\hline Low-intensity & 1.13 & 0.65 & 1.98 \\
\hline \multicolumn{4}{|l|}{ Morgan et al., 2011} \\
\hline Mass-media + inter-personal & 2.59 & 0.88 & 7.65 \\
\hline Mass media only & 1.21 & 0.36 & 4.11 \\
\hline \multicolumn{4}{|l|}{ O'Carroll et al., 2011} \\
\hline Anticipated Regret & 1.87 & 0.88 & 3.96 \\
\hline Theory of Planned Behaviour & 0.57 & 0.23 & 1.46 \\
\hline
\end{tabular}




\begin{tabular}{|c|c|c|c|}
\hline \multicolumn{4}{|l|}{ Quinn et al., 2006} \\
\hline Enhanced & 2.19 & 1.12 & 4.30 \\
\hline Basic & 1.99 & 1.01 & 3.93 \\
\hline Resnicow et al., 2010 & 2.47 & 0.46 & 13.17 \\
\hline Rodrigue et al., 2012 & 11.00 & 1.38 & 87.64 \\
\hline \multicolumn{4}{|l|}{ Sanner et al., 1995} \\
\hline Campaign B & 2.59 & 0.88 & 7.65 \\
\hline Campaign $\mathrm{C}$ & 2.84 & 0.97 & 8.29 \\
\hline Siegel et al., 2008 & N/A & N/A & N/A \\
\hline Thornton et al., 2012 & 2.04 & 1.02 & 4.07 \\
\hline Vinokur et al., 2006 & 1.50 & 0.73 & 3.07 \\
\hline \multicolumn{4}{|l|}{ Winkel, 1984} \\
\hline Refutational & 1.80 & 0.99 & 3.27 \\
\hline Conventional & 1.39 & 0.76 & 2.55 \\
\hline \multicolumn{4}{|c|}{ Winkel \& Huismans, 1986} \\
\hline Low Denial & 2.51 & 1.23 & 5.11 \\
\hline High Denial & N/A & N/A & N/A \\
\hline
\end{tabular}

Note. Odds ratios reported represent relative likelihood that a participant in the intervention condition registered as an organ donor. 